\title{
Hydroxyethyl starch should not be used to manage severe aluminium phosphide poisoning
}

\author{
Zvonko Rumboldt \\ Split University School of Medicine, Split, Croatia
}

In the Archives January issue (1), I have read with interest and surprise a letter by Marashi and Nasrabadi concerning the use of hydroxyethyl starch (HES, hetastarch; best known under the registered name Plasmasteril) to treat severe aluminium phosphide (AlP) poisoning.

At the current level of scientific evidence such a claim seems unacceptable.

Aluminium phosphide poisoning (the compound is commercially available as a fumigant for stored cereals) is believed to be caused by phosphine $\left(\mathrm{PH}_{3}\right)$, as it induces mitochondrial damage and severe multi-organ failure (2). The poisoning is mostly reported from the Indian subcontinent, and is largely unknown in Europe. The management is exclusively supportive (gastric lavage with $\mathrm{KMnO}_{4}$ solution, treatment of shock, lactic acidosis, etc.), since there is no specific antidote $(2,3)$. Some traditional (e.g. coconut oil) or "modern" interventions (e.g. haemodialysis) have not been adequately assessed, and rest instead on pathophysiological assumptions, anecdotal reports, and wishful thinking $(2,3)$.

Lactic acidosis type A, a form of high anion gap metabolic acidosis, is just one of the many aspects of AlP poisoning with fatal prognosis. Treatment with $\mathrm{NaHCO}_{3}$ in this situation is highly controversial, as the authors (1) appropriately underscore. However, the suggested administration of colloid solutions is potentially even more dangerous. The authors corroborate their proposal by quoting just one hypothetic paper of their own on the role of HES in acute AlP poisoning (4) with no further experimental evidence. It is not clear whether they are advocating starch solution administration at arterial $\mathrm{pH}>7$ (as stated in the letter) or $<7$, or what the dosage of 500$1000 \mathrm{~mL}$ of HES really means (i.e. isotonic, $6 \mathrm{~g} \mathrm{~L}^{-1}$, or hypertonic, $9 \mathrm{~g} \mathrm{~L}^{-1}$ solution)?

Contrary to their claim (1), colloidal solutions such as dextrans, pentastarch, polygeline, and HES in particular may worsen metabolic acidosis and shock, possibly due to the substance's deposition in the tissue and its interaction with fibrinogen, leading to even more severe coagulopathy and organ failure (5). Crystalloid solutions are better tolerated and equally effective plasma expanders (6).

Beware of ill-founded therapeutic enthusiasm!

\section{REFERENCES}

1. Marashi SM, Nasri-Nasrabadi Z. Can sodium bicarbonate really help in treating metabolic acidosis caused by aluminium phosphide poisoning? Arh Hig Rada Toksikol 2015;66:83-4. doi: 10.1515/aiht-2015-66-2637

2. Agrawal VK, Bansal A, Singh RK, Kumawat BL, Mahajan P. Aluminium phosphide poisoning: possible role of supportive measures in the absence of specific antidote. Indian J Crit Care Med 2015;19:109-12. doi: 10.4103/09725229.151019

3. Gurjar M, Baronia AK, Azim A, Sharma K. Managing aluminium phosphide poisoning. J Emerg Trauma Shock 2011;4:378-84. doi: 10.4103/0974-2700.83868

4. Marashi SM, Arefi M, Behnoush B, Nasrabad MG, Nasri Nasrabadi Z. Could hydrohyethyl starch be a therapeutic option in the management of acute aluminium phosphide toxicity. Med Hypotheses 2011;76:596-8. doi: 10.1016/j. mehy.2011.01.009

5. Hartog CS, Natanson C, Sun J, Klein HG, Reinhart K. Concerns over use of hydroxyethyl starch solutions. BMJ 2014;349:g5891. doi: 10.1136/bmj.g5981

6. The European Medicines Agency's Pharmacovigilance Risk Assessment Committee. Hydroxyethyl-starch solutions (HES) should no longer be used in patients with sepsis or burn injuries or in critically ill patients [displayed 14 July 2015]. Available at: http://www.ema.europa.eu/ema/index. jsp?curl=pages $/$ medicines/human/referrals/Hydroxyethyl_ starch-containing_solutions/human_referral_prac_000012. jsp\&mid=WC0b01ac0580 5c516f 